
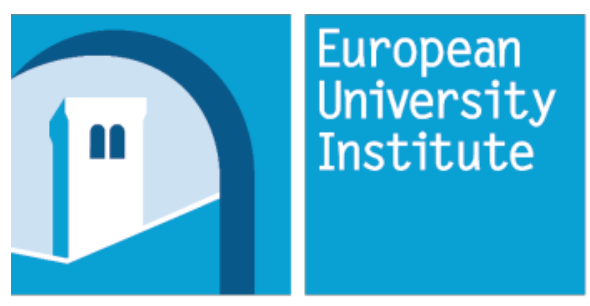

DEPARTMENT

OF

ECONOMICS
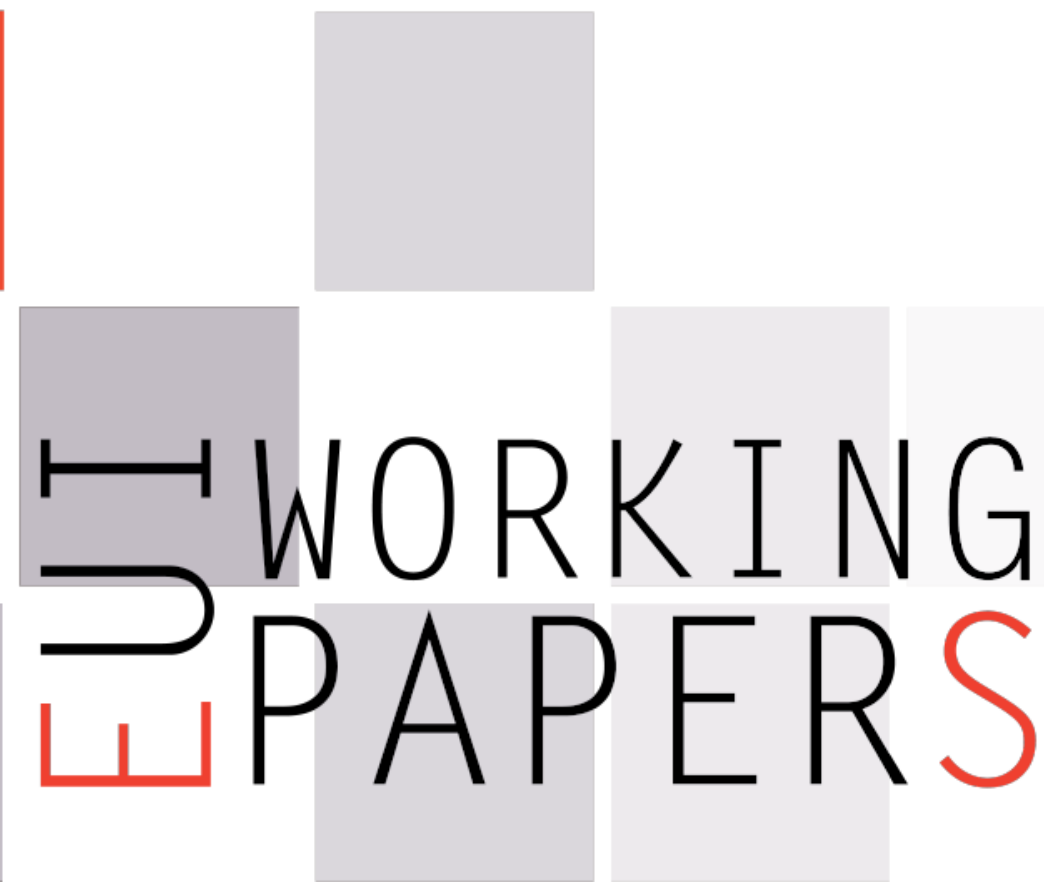

ECO 2016/12

Department of Economics

Missing Consumption Inequality: Direct Evidence from Individual Food Data

Raül Santaeulàlia-Llopis and Yu Zheng 

European University Institute

Department of Economics

Missing Consumption Inequality: Direct Evidence from Individual Food Data

Raül Santaeulàlia-Llopis and Yu Zheng

EUI Working Paper ECO 2016/12 
This text may be downloaded for personal research purposes only. Any additional reproduction for other purposes, whether in hard copy or electronically, requires the consent of the author(s), editor(s). If cited or quoted, reference should be made to the full name of the author(s), editor(s), the title, the working paper or other series, the year, and the publisher.

ISSN 1725-6704

(C) Raül Santaeulàlia-Llopis and Yu Zheng, 2016

Printed in Italy

European University Institute

Badia Fiesolana

I - 50014 San Domenico di Fiesole (FI)

Italy

www.eui.eu

cadmus.eui.eu 


\title{
Missing Consumption Inequality: Direct Evidence from Individual Food Data*
}

\author{
Raül Santaeulàlia-Llopis \\ MOVE-UAB and Barcelona GSE \\ Universitat de València
}

\author{
Yu Zheng \\ City University of Hong Kong \\ European University Institute
}

August 4, 2016

\begin{abstract}
Without data on individual consumption, inequality across individuals is almost invariably inferred by applying adult equivalence scales to household-level consumption data. To assess whether these household-based measures are effective, we exploit a rare opportunity in which individual food consumption data for each and all household members are available. We use a large sample of eight waves of the China Health and Nutrition Survey 1991-2011 that cover roughly 4,000 households and 11,000 individuals per wave. We find that adult-equivalent consumption misses $40 \%$ of the total cross-sectional individual inequality. The missing inequality is largely driven by the "vices" (i.e. alcohol, tobacco, coffee and tea) and by the core food consumption of young children. Our results suggest caution in the use of adult-equivalent scales to measure inequality, whose effectiveness depends on the items in the consumption basket and the presence of young children.
\end{abstract}

Keywords: Consumption, Inequality, Adult Equivalence, Scales, Individual Data JEL Classification: D12, E21

*We would like to thank Leandro De Magalhaes, Isis Gaddis, and Cynthia Kinnan for very useful comments. We would also like to thank the research assistance of Jonas Jin. 


\section{Introduction}

For lack of individual consumption data, the study of consumption inequality almost invariably focuses on adult-equivalent measures (Deaton and Paxson, 1994, Attanasio and Weber, 1995, Krueger and Perri, 2006, Blundell et al., 2008, Krueger et al., 2010). ${ }^{1}$ Adult-equivalent consumption is a household-based measure that adjusts household-level consumption data by household structure using equivalence scales. These scales take into account the age and sex structure of a household to infer the individual consumption of a reference household member, e.g. the head, out of the household-level consumption data. ${ }^{2}$ But, how much does adult-equivalent consumption capture of the actual individual consumption inequality? To answer this question we take full advantage of a new and rare opportunity to directly measure individual inequality using actual individual-level food consumption data collected for each and all household members in a large sample of households. We exploit these data to quantitatively assess the performance of standard adult-equivalent household measures in capturing actual individual food consumption inequality. Our source is the China Health and Nutrition Survey recently used in Wang (2011) and Santaeulàlia-Llopis and Zheng (2016) that covers nine provinces of China from 1991 to 2011 with roughly 32,000 household observations and 88,000 individual observations of food consumption uniformly distributed across eight waves. ${ }^{3}$

Our first finding is that the adult-equivalent food consumption inequality roughly misses $40 \%$ of the actual cross-sectional individual consumption inequality in both rural and urban areas. Second, the missing inequality inferred from equivalized household-level measures comes mainly from the failure of the equivalence scales to account for the consumption inequality of alcohol, tobacco, coffee and tea (or more conveniently the "vices") among adults. Once we exclude the vices from the food consumption, adult-equivalent consumption misses roughly $17 \%$ of actual individual inequality. That is, the vices account for $57 \%$ of the total missing inequality. Third, our analysis of the lifecycle inequality with individual data shows that food consumption inequality among children (in particular, children 0 to 5 years of age) roughly doubles that of adults. After controlling for vices and children, the amount of consumption inequality that adult-equivalent measures miss of actual individual inequality drops to $5 \%$. That is, children account for $30 \%$ of the total missing inequality. This leaves roughly $13 \%$ of the missing consumption inequality

\footnotetext{
${ }^{1}$ We use interchangeably the concept of consumption and expenditure. For a explicit separation between these two concepts, see Aguiar and Hurst (2005).

${ }^{2}$ Fernández-Villaverde and Krueger (2007) provide a comprehensive review of alternative scales for nondurable and durable consumption. See also Bick and Choi (2013) for a more recent discusion on the role of the household structure over the life cycle in incomplete markets models.

${ }^{3}$ These nine provinces are the most consistently surveyed provinces since 1991 and represent $41 \%$ of the total population in China in 2011.
} 
unexplained for our entire sample. Our results are robust to the use of caloric intake as measure of individual consumption, and therefore are robust to the choice of consumption prices.

To the best of our knowledge, ours is the first exercise that uses direct evidence of individual consumption inequality to evaluate adult-equivalent measures of consumption inequality. The reason is simple: household surveys are largely designed to capture consumption at the householdlevel and information on actual individual consumption-which is more costly to collect-is not typically collected (Grosh and Deaton, 2000, Beegle et al., 2016). This makes the person-level food consumption data that we use from the CHNS ideal for our study.

Previously, the consumption literature has proposed ways to overcome the lack of individual data. Lise and Seitz (2011) use a collective model to structurally recover individual consumption. ${ }^{4}$ These authors find that the inferred individual consumption inequality is twice what householdlevel consumption data implies for the United Kingdom. Theirs is a larger discrepancy than what we find, which suggests that, perhaps, our measure of individual inequality based on food consumption is likely to generate a lower bound. Also related to our work, Dunbar et al. (2013) use information about clothing expenditures across children and adults within households in Malawi to recover the structure of total consumption through the lens of a collective model and find that child poverty is underestimated with standard poverty indices. More recently, DeVreyer and Lambert (2016) study the unusual compound structure within households in Senegal to infer individual consumption. ${ }^{5}$ In contrast to this literature, our approach is, perhaps, more direct as we take on an uncommon opportunity to measure actual individual consumption. The fact that we focus on food also makes our analysis arguably less subject to measurement error (Aguiar and Bils, 2011, Attanasio et al., 2014, Carroll et al., 2014).

The exceptions in which previous work has studied individual consumption data largely focus on nutrion intake in developing countries (Behrman and Deolalikar, 1990, Pitt et al., 1990, Behrman, 1993, Haddad et al., 1997). ${ }^{6,7}$ In this direction, closely related to our work, Haddad and Kanbur (1990) find that inequality in calorie intake across households can underestimate actual individual inequality by roughly one third in a rural province of southern Philippines for 1984-5.

\footnotetext{
${ }^{4}$ The use of collective models to identify sharing rules from household-level data is not trivial (Browning et al., 2013, Cherchyey et al., 2015). When only household-level consumption data are available, collective models add structure to determine person-level welfare. Precisely, persons' consumption allocations are endogenously determined through functions that map individual wages, labor supply decisions, altruism, heterogenous preferences, or other factors into person-level consumption; see the recent review in Chiappori and Meghir (2014).

${ }^{5}$ See also Lambert et al. (2014).

${ }^{6}$ The focus on food consumption is particularly interesting for poor countries where food is the largest component of the consumption basket. For example, in India and Pakistan a large proportion of households spend $75 \%$ of their expenditure on food (Deaton, 1997). In Malawi, Uganda and Tanzania food expenditure represents roughly two thirds of the total expenditure (De Magalhães and Santaeulàlia-Llopis, 2015).

${ }^{7}$ See also the more recent discussion in Alderman et al. (2008).
} 
More recently, in a developed context, Lise and Yamada (2014) estimate intrahousehold sharing rules using a larger basket of nondurable individual consumption data from Japan. However, none of these studies analyzes the size of cross-sectional individual inequality and the ability of adult-equivalent consumption measures to capture it, which is the focus of our study.

It is important to note that focusing on food consumption-certainly the closest one can get to a pure private good-helps us circumvent the potential issue of economies of scale associated with public good consumption within a household (Nelson, 1988, Deaton and Paxson, 1998). In the absence of economies of scale, linear equivalence scales are a natural choice. We take as our benchmark the linear scales from the regression-based approach in Aguiar and Hurst (2013). ${ }^{8}$ This approach has the advantage that it can produce the equivalence scale specific to a consumption item or a group of items, such as the vices, the food consumption except the vices (or more conveniently the "core" food) and caloric intake. A caveat of the regression-based approach is that it assumes that the equivalence scales are exogenous (Fernández-Villaverde and Krueger, 2007). There are modelling options that explicitly deal with the potential endogeneity issues such as family formation (Salcedo et al., 2012). Interesting identification strategies have been used to structurally estimate equivalence scales using individual life insurance choices (Hong and Ríos-Rull, 2012) or collective models with economies of scale and intrahousehold sharing rules (Browning et al., 2013). Another compelling strategy to estimate equivalence scales is the use of the distributional patterns of welfare programs, in which case the scales are not determined by the household but by the community distributing aid (Olken, 2005).

The rest of the paper is organized as follows. Section 2 describes the data set, the construction of measures of consumption, and patterns of family composition across time and space in China. We discuss the construction of adult-equivalent consumption, the standard householdbased measure of consumption, and its computation in Section 3. In Section 4, we quantitatively assess the effectiveness of adult-equivalent consumption inequality in capturing actual individual consumption inequality. We also investigate the sources of discrepancies. Section 5 concludes.

\section{The Data}

The China Health and Nutrition Survey (CHNS) is an on-going project between the Carolina Population Center at the University of North Carolina at Chapel Hill and the National Institute of Nutrition and Food Safety at the Chinese Center for Disease Control and Prevention. It strated collecting diet, health, demographic and socio-economic information from about 4,000 Chinese households living in nine geographically diverse provinces since 1989. In this study, we

\footnotetext{
${ }^{8}$ Note that the OECD scales are also linear equivalence scales.
} 
use the most recent eight waves of the CHNS conducted in 1991, 1993, 1997, 2000, 2004, 2006, 2009, and 2011, and in the most consistently surveyed provinces, Liaoning, Heilongjiang, Jiangsu, Shandong, Henan, Hubei, Hunan, Guangxi, and Guizhou. ${ }^{9}$ This gives us a sample of roughly 88,000 individuals living in 32,000 households uniformly distributed across waves.

The Nutrition Survey, an integral part of the CHNS, documents a variety of food items that each and all household members consume (in grams), both at home and away from home, over a three-day window. The result is a highly detailed account of hundreds of types of food consumed during the day, whose precision is suitable for nutrition studies (Batis et al., 2014). This survey design minimizes recall and telescoping error and is considered close to a "gold standard" for measuring consumption (Deaton and Zaidi, 2002, Beegle et al., 2010). This constitutes what we call the core food component. In addition, we construct a "vice" component of food consumption, which includes alcohol, tobacco, coffee and tea. The quantity of the vices for all individuals age 12 and above was collected from the Physical Examination Survey in 1991, 1993 and 2000, in Household Survey in 1997, and in the Adult/Child Survey after 2004.

We match these quantity data with the local prices of the core and the vices, from the Community Survey, to obtain the expenditures of the two components respectively. ${ }^{10}$ To ensure comparability over time, we report expenditures in constant 2009 food prices. Finally, to isolate the price effects, we also construct the individual daily calory intake from the quantity data. To convert food intake into calorie consumption, we follow the suggestion from the CHNS team and use the conversion rates from food items to calories published in the China Food Composition Tables. In addition to food consumption, the CHNS also has rich information about the demographic and socio-economic characteristics of the individuals. We refer the reader to Santaeulàlia-Llopis and Zheng (2016) for detailed description of the survey method and data construction.

We trim the top $1 \%$ of the core food expenditure by wave and by urban status. We trim the top and bottom $1 \%$ of the calorie consumption of individuals age 14 and above by wave and gender. We drop individuals that have missing information on both calorie and core food expenditure. We drop individuals that have missing age or gender information. The householdlevel measures are aggregated from the individual data. We further keep individuals from the sixteen most common types of household compositions that range from 1-person households to 6 -person households, which make up $94.5 \%$ of the remaining sample. Our analysis sample is an

\footnotetext{
${ }^{9}$ We exclude the first 1989 wave due to a significant change in the design of the Nutrition Survey in 1991. We also exclude the three megacities, Beijing, Shanghai and Chongqing, which were introduced only in 2011.

${ }^{10}$ The CHNS staff collects the prices of a variety of consumption items from local supermarkets and free markets. We take the average of available prices from different local sources for a given food item and use it to compute the expenditure on that item.
} 
unbalanced panel of 6,949 households and 26,581 individuals. ${ }^{11}$

The summary statistics from the analysis sample are found in Table 1 . Due to the panel nature of our dataset, the average age increases from 31 in 1991 to 46 in 2011 . The household size decreases by almost one person per household, from an average of 3.92 in 1991 to 2.95 in 2011. The average weak dependency ratio, i.e. the number of children (age less than 15) over the number of adults (age 15 and above), decreases from 0.45 in 1991 to 0.19 in 2011. The strong dependency ratio, i.e. the number of children (age less than 15) and old adults (age above 60 ) over the number of working age adults (age in between 15 and 60), decreases also, albeit to a lesser extent, from 0.65 in 1991 to 0.49 in 2011 . These changes in household composition occur in both the rural and urban sample (see Table 1).

We document the evolution of various measures of cross-sectional and lifecycle inequality of food consumption in the next section. Specifically, we assess how effective adult-equivalent measures are in capturing actual individual inequality, and that is the point of this paper.

\section{The Household-Based Measure: Adult-Equivalent Consumption}

In the studies on consumption inequality, the researcher often only has access to household-level expenditure data. As welfare is typically defined for an individual (instead of a household), the common practice is to convert household-level consumption into individual-level consumption using equivalence scales. In particular, given that we focus on private food consumption, we study linear equivalence scales.

Traditionally, the linear scale $\theta_{g, a}$ captures the inverse of the ratio between the consumption of a reference member in the household and the consumption of some non-reference household member of gender $g$ and age $a$. Considering the household head as the reference, the equivalence scale for a non-head individual is defined by the approximation $\frac{c_{g, a}^{i}}{c^{h}} \approx \theta_{a, g}$, where $c^{h}$ is the consumption of the household head and $c_{g, a}^{i}$ is the consumption of the non-head household member $i$ of gender $g$ and age $a$. This way, given household consumption $C$,

$$
C=c^{h}+\sum_{i \neq h} c^{i}
$$

\footnotetext{
${ }^{11}$ There are 77 observations with missing calorie and core food expenditure. There are 38 observations with missing age or gender information. We drop those. The most common household composition in 1991 consists of "two adults and two children", which takes up $20 \%$ of individuals in that wave. The most common household composition in 2000 consists of "two adults and one child", which also takes up 20\%. By 2011, the most common household composition has evolved to consist of "two adults" and 35\% of individuals in that wave lived in such a household.
} 
we can approximate the consumption of the adult reference member as

$$
c^{h} \approx \frac{C}{1+\sum_{i \neq h}^{I} \mathbf{1}_{i \in\{g, a\}} \theta_{g, a}} .
$$

We refer to $c^{h}$ as the adult-equivalent consumption. Note that only information on householdlevel consumption, $C$, and on the household composition are needed to define adult-equivalent consumption, $c^{h}$.

As our benchmark equivalence scale, we proceed similarly to Aguiar and Hurst (2013) and regress the logged household-level consumption measure on dummies for the number of adults and the number of children of different genders and ages: ${ }^{12}$

$$
\ln C=\text { cons }+\beta_{\text {adults }} \mathbf{1}_{\# \text { adults }}+\sum_{i \neq a d u l t}^{I} \mathbf{1}_{i \in\{g, a\}} \beta_{g, a}
$$

The regression is run separately by area of residence (i.e. rural or urban) and by wave. Then we use the exponentiated predicted value of the regression, normalized by the value for singleton households (i.e. the exponentiated constant in the above regression), as the equivalence scale.

\section{Adult-Equivalent Consumption Inequality vs. Actual Individual Con- sumption Inequality}

Our dataset, which contains actual individual food consumption, provides us with the rare opportunity to examine whether adult-equivalent consumption measures are effective in capturing actual individual consumption inequality. We assess this effectiveness in the cross-section and over the life cycle. We explore the role of the vices and children.

\subsection{The Cross-Section}

We use two measures of food consumption inequality to explore the cross-sectional variance of (logged) food consumption for rural and urban areas separately. The first measure of inequality is our benchmark adult-equivalent consumption constructed from the household-level data as described in the previous section. The second measure of inequality uses the actual individual consumption data from each and all household members of the household.

\footnotetext{
${ }^{12}$ The dummies $\mathbf{1}_{i \in\{g, a\}}$ include the dummies for the number of boys between 0 and 2, the number of girls between 0 and 2, the number of boys between 3 and 5, the number of girls between 3 and 5, the number of boys between 6 and 13, the number of girls between 6 and 13, the number of boys between 14 and 17, and the number of girls btween 14 and 17 .
} 
The difference between the two inequality measures is striking. The adult-equivalent consumption inequality is substantially lower than the individual consumption inequality. For the rural sample, averaging across years, the variance of logged individual food consumption is $\operatorname{var}\left(\ln c^{i}\right)=0.744$ and the variance of logged adult-equivalent inequality is $\operatorname{var}\left(\ln c^{h}\right)=0.436$ (panel (a), Table 2). This implies that adult-equivalent consumption inequality misses $\sum_{t} 100 \times$ $\left(1-\frac{\operatorname{var}_{t}\left(\ln c^{h}\right)}{\operatorname{var}_{t}\left(\ln c^{i}\right)}\right)=41.48 \%$ of the individual inequality. This is consistent across years: Adultequivalent consumption inequality misses $48 \%$ of the individual inequality in 1991 and $41 \%$ in 2011 (panel (a), Figure 1). The picture is similar for the urban sample, where, averaging across years, the variance of logged individual food consumption is 0.572 and the variance of logged adult-equivalent inequality is 0.355 (panel (a), Table 2). That is, adult-equivalent consumption inequality misses $37.71 \%$ of the individual inequality. A closer look at different years shows similar results with adult-equivalent consumption missing $42 \%$ of the individual inequality in 1991 and $39 \%$ in 2011 (panel (b), Figure 1). To sum up, across time and space, the adult-equivalent consumption inequality roughly misses $40 \%$ of the actual individual consumption inequality. ${ }^{13}$

\subsection{The Role of the Vices}

Between the two components of food expenditure, one would expect the core food consumption to vary less across households with a similar structure than the vices. Intuitively, the consumption of vices can capture more the heterogeneity of preferences or can be associated more with work, and hence can potentially vary more even within similar demographic groups (Aguiar and Hurst, 2013). We next show that this is exactly the case. The discrepency between the adult-equivalent consumption inequality and individual inequality is largely driven by the vices.

To evaluate how the vices affect the inequality measures, we reconduct our inequality analysis using the core food component in isolation. For the rural sample, averaging across years, the variance of logged individual core food consumption is 0.311 and the variance of logged adult-equivalent consumption is 0.252 (panel (b), Table 2). That is, adult-equivalent core food consumption inequality misses $19.26 \%$ of the actual individual inequality in rural areas. This implies that the vices explain $100 \times(41.5-19.3) / 41.5=54 \%$ of the missing inequality in rural areas. Similar insights emerge from the urban sample where, averaging across years, the variance of logged individual core food consumption is 0.275 and the variance of logged adult-equivalent consumption is 0.234 (panel (b), Table 2). That is, adult-equivalent core food consumption inequality misses $14.76 \%$ of the actual individual inequality in urban areas. This implies that the vices explain $61 \%$ of the missing inequality in rural areas. The contrast between panels (a) and (c) and between panels (b) and (d) in Figure 2 confirms that the role of the vices is quantita-

\footnotetext{
${ }^{13}$ Our results are vey similar using modified OECD scales.
} 
tively important across years for both rural and urban areas. To sum up, excluding the vices, the adult-equivalent consumption misses roughly $17 \%$ of actual individual inequality across time and space. That is, the vices roughly account for $57 \%$ of the missing consumption inequality.

\subsection{The Life Cycle}

The age profiles provide additional insights on the potential sources of missing consumption inequality. We contrast the standard measure of adult-equivalent consumption inequality over the life cycle (Heathcote et al., 2005) with our benchmark individual consumption inequality over the life cycle. To obtain the standard measure, we regress the logged adult-equivalent food consumption on dummies of the cohort of the head and compute the variance of the residuals from the resulting regression by the age of the household head. ${ }^{14}$ To construct our benchmark measure of individual inequality over the life cycle, we index the individual food consumption of each and all household members by the age of their corresponding household head, regress logged individual consumption on the head's cohort, and compute the variance of the residuals from the resulting regression by the age of the household head. We deliberately choose to group the individual data by the age of the household head to make a consistent comparison with the adult-equivalent inequality. The two inequality measures are plotted in solid curves in the top panels (a) and (b) of Figure 2 for rural and urban areas, where we fit a cubic spline on the variances indexed by the head's age.

Our results show that the variance of adult-equivalent food consumption is relatively flat with an absolute growth of 0.1 of log points, a feature shared by food consumption over the life cycle in the U.S. (Aguiar and Hurst, 2013). ${ }^{15}$ The individual inequality exhibits growth over the life cycle by a similar magnitude, roughly by $0.1 \mathrm{log}$ points. What is relevant is that, similar to our cross-sectional findings, adult-equivalent consumption inequality misses roughly $40 \%$ of the individual inequality over the life cycle in both rural and urban areas.

Consistent with the role of vices we explored in a cross-sectional setting, when we exclude the vices, the adult-equivalent food consumption inequality over the life cycle is also much closer to

\footnotetext{
${ }^{14}$ Heathcote et al. (2005) show that the age-profile of inequality can look different depending on if one controls for time effects or for cohort effects. In our case, the age-profile of food consumption inequality remains largely invariant to the control for time or cohort effects. We report the results with cohort controls in the main text and relegate the results with time controls to the online Appendix ??.

${ }^{15}$ In the US, Aguiar and Hurst (2013) documents an age profile for the cross-sectional variance of food at home that decreases by $-0.04 \log$ points between the ages of 25 and 45 , and increases by 0.01 log points between the ages of 45 and 65 . The cross-sectional variance of food away from home decreases by -0.08 log points between the ages of 25 and 45, and increases by $1.60 \mathrm{log}$ points between the ages of 45 and 65 . The cross-sectional variance of acohol and tobacco shows a much larger rise over the life cycle increasing by 1.61 log points between the ages of 25 and 45 , and by 3.21 log points between the ages of 45 and 65 .
} 
the individual inequality over the life cycle (panels (c) and (d) in Figure 2). On average, the vices close the gap between the adult-equivalent and the individual inequality by $60 \%$. Interestingly, while the amount of missing core food consumption inequality is roughly $25 \%$ at ages 25 to 30 , it decreases with the head's age and entirely disappears in old ages. In other words, there is sizeable within household core food consumption inequality not accounted for by the scales for younger households, but not older households. This points to core food consumption inequality among children across households as a potential explanation, which we explore next.

\subsection{The Role of Children}

To gain a better understanding of the effects of the households' age structure on the amount of missing inequality, we construct an additional measure of inequality. By this measure, which we label as "Individual (own age)", we compute the inequality of individuals of the same age, independently of the household membership. To do this, we regress logged individual consumption on the individual's cohort, and compute the variance of the residuals from the resulting regression by the age of the individual. We do this for each age group from children aged 0 (i.e., less than 1 year old) to adults of age 80 . We plot this measure together with the adult-equivalent and the individual inequality measures in Figure 2.

Focus on panels (c) and (d) in Figure 2, the case of core food consumption. Without the vices, "Individual (own age)" consumption inequality practically overlaps with adult-equivalent consumption inequality for the adults aged 25 or older, while consumption inequality remains high for children at young ages. "Individual (own age)" consumption inequality for children aged 0 to 5 is roughly twice larger than that for adults aged 25 or older. In other words, the individual inequality, that is the inequality across all members of households whose heads are of a given age, is also higher than the inequality across adults of a similar age. To the extent that the younger households tend to have children at very young age and there is a much higher level of inequality among children than among adults, the missing individual inequality in core food consumption is likely driven by the presence of children.

One way to test this hypothesis is to restrict our attention to a sample of households without children. ${ }^{16}$ We start from the cross-sectional results (Table 3). Without children, the amount of consumption inequality that adult-equivalent measures miss with respect to individual measures is roughly $29.65 \%$ in rural areas and $26.96 \%$ in urban areas (panel (a) Table 3). Further removing the vices, we find the amount of missing inequality substantially drops to barely $5.32 \%$ in rural

\footnotetext{
${ }^{16}$ Our results are very similar if instead of restricting the sample to households without children, we remove all children from our analysis. That is, if we use all adults, independently of whether they have children or not, to construct individual inequality. See online Appendix ??.
} 
and $4.70 \%$ in urban areas. In other words, removing households with children, we can reduce the missing core food consumption inequality from 19.26 to 5.32 for the rural sample and from 14.76 to 4.70 for the urban sample. This implies that accounting for children further reduces the missing consumption inequality by $(19.3-5.3) / 41.2=34 \%$ in rural areas and $(14.8-4.7) / 37.7=27 \%$ in urban areas, where $41.2 \%$ and $37.7 \%$ are the total missing inequality documented in panel (a) of Table 2. This result is consistent across years and over the life cycle (see panel (a) and (c) of Figure 3). Without vices or children, adult-equivalent inequality and individual inequality basically overlap. Moreover, this result is robust to consumption prices. We investigate the inequality in caloric intake from the core food component à la Aguiar and Hurst (2005) and find that while inequality in caloric intake is roughly one third of that of consumption expenditure, suggesting an important role for prices in the absolute level of inequality, adult-equivalent inequality accurately measures individual inequality after controlling for children both cross-sectionally and over the life cycle (see panel (b) and (d) of Figure 3).

The role of children is robust to further household structure controls. Focusing on either core food consumption (panel (a) Figure 4) or calorie intake (panel (b) Figure 4) of households with three members (i.e. a head, a spouse and a child), we find that the inequality among adults (i.e., the parents) across households largely overlaps with the adult-equivalent inequality, while the inequality among children across households is much higher for young households and declines as heads age. That is, for the sample of three-member households the vices and children explain most of, in not all, the missing food consumption inequality.

\section{Conclusion}

Standard adult-equivalent measures of consumption miss $40 \%$ of the total cross-sectional individual food consumption inequality. Our findings emerge from the study of unique individual data for a large sample of individuals and years. The vices component of the diet (i.e. alcohol, tobacco, coffee and tea) accounts for $57 \%$ of the missing inequality, and the core food consumption of young children accounts for another $30 \%$ of the missing inequality.

Our results suggest caution in the use of adult-equivalent consumption to measure inequality, whose effectiveness strictly depends on the items in the consumption basket and the presence of young children. This provides a practical lesson for consumption data collection: To increase the accuracy in the measurement of consumption inequality, household surveys might greatly benefit from collecting individual data on the vices from adults and on the core food items from children, while keeping the current practice of household-level data collection of core food items for adults. Obviously, the study of intrahousehold allocations between spouses would still benefit 
from separate individual consumption data for each spouse. ${ }^{17}$ In this direction, we expect our data to be useful to identify intrahousehold sharing rules, as recently pioneered by Lise and Yamada (2014) also using individual consumption data, as well as to identify intrahousehold insurance mechanisms. We leave these important questions for future research.

\section{References}

Aguiar, M. and Hurst, E. (2005). Consumption versus Expenditure. Journal of Political Economy, 113(5):919-948.

Aguiar, M. and Hurst, E. (2013). Deconstructing Life Cycle Expenditure. Journal of Political Economy, 121(3):437-492.

Aguiar, M. A. and Bils, M. (2011). Has Consumption Inequality Mirrored Income Inequality? NBER Working Papers 16807, National Bureau of Economic Research, Inc.

Alderman, H., Behrman, J. R., and Hoddinott, J. (2008). Health and Nutrition and Economic Development. In International Handbook of Development Economics, Volumes 1 \& 2, Chapters, chapter 25. Edward Elgar Publishing.

Attanasio, O., Hurst, E., and Pistaferri, L. (2014). The Evolution of Income, Consumption, and Leisure Inequality in the US, 1980-2010. In Improving the Measurement of Consumer Expenditures, NBER Chapters. National Bureau of Economic Research, Inc.

Attanasio, O. P. and Weber, G. (1995). Is Consumption Growth Consistent with Intertemporal Optimization? Evidence from the Consumer Expenditure Survey. Journal of Political Economy, 103(6):11211157.

Batis, C., Sotres-Alvarez, D., Gordon-Larsen, P., Mendez, M., and Popkin, B. M. (2014). Longitudinal Analysis of Dietary Patterns in Chinese Adults from 1991 to 2009. British Journal of Nutrition, 111(8):1441-51.

Beegle, K., Christiansen, L., Dabalen, A., and Gaddis, I. (2016). In Poverty in a Rising Africa, chapter 4. World Bank.

Beegle, K., DeWeerdt, J., Friedman, J., and Gibson, J. (2010). Methods of Household Consumption Measurement through Surveys: Experimental Results from Tanzania. Policy Research Working Paper, The World Bank.

Behrman, J. R. (1993). Intrahousehold Distribution and the Family. In Rosenzweig, M. R. and Stark, O., editors, Handbook of Population and Family Economics, volume 1 of Handbook of Population and Family Economics, chapter 4, pages 125-187. Elsevier.

Behrman, J. R. and Deolalikar, A. B. (1990). The Intrahousehold Demand for Nutrients in Rural South India: Individual Estimates, Fixed Effects, and Permanent Income. Journal of Human Resources, 25(4):665-696.

\footnotetext{
${ }^{17}$ See Case and Deaton (2003) for a discussion and alternatives that, in the absence of individual consumption data, link family expenditure patterns to the gender composition of the household.
} 
Bick, A. and Choi, S. (2013). Revisiting the Effect of Household Size on Consumption over the LifeCycle. Journal of Economic Dynamics and Control, 37(12):2998-3011.

Blundell, R., Pistaferri, L., and Preston, I. (2008). Consumption Inequality and Partial Insurance. American Economic Review, 98(5):1887-1927.

Browning, M., Chiappori, P.-A., and Lewbel, A. (2013). Estimating Consumption Economies of Scale, Adult Equivalence Scales, and Household Bargaining Power. Review of Economic Studies, 80(4):12671303.

Carroll, C. D., Parker, J. A., and Souleles, N. S. (2014). The Benefits of Panel Data in Consumer Expenditure Surveys. In Improving the Measurement of Consumer Expenditures, NBER Chapters. National Bureau of Economic Research, Inc.

Case, A. and Deaton, A. (2003). Consumption, Health, Gender, and Poverty. Policy Research Working Paper Series 3020, The World Bank.

Cherchyey, L., DeRockz, B., Lewbelxand, A., and Vermeulen, F. (2015). Sharing Rule Identification for General Collective Consumption Models. Forthcoming, Econometrica.

Chiappori, P.-A. and Meghir, C. (2014). Intrahousehold Inequality. Cowles Foundation Discussion Papers 1948, Cowles Foundation for Research in Economics, Yale University.

De Magalhães, L. and Santaeulàlia-Llopis, R. (2015). The Consumption, Income, and Wealth of the Poorest: Cross-Sectional Facts of Rural and Urban Sub-Saharan Africa for Macroeconomists. World Bank, Policy Research Working Paper 7337.

Deaton, A. (1997). The Analysis of Household Surveys: A Microeconometric Approach to Development Policy. The John Hopkins University Press.

Deaton, A. and Paxson, C. (1994). Intertemporal Choice and Inequality. Journal of Political Economy, 102(3):437-467.

Deaton, A. and Paxson, C. (1998). Economies of Scale, Household Size, and the Demand for Food. Journal of Political Economy, 106(5):897-930.

Deaton, A. and Zaidi, S. (2002). Guidelines for Constructing Consumption Aggregates for Welfare Analysis. Number 14101 in World Bank Publications. The World Bank.

DeVreyer, P. and Lambert, S. (2016). Intrahousehold Inequalities and Poverty in Senegal. Technical report.

Dunbar, G. R., Lewbel, A., and Pendakur, K. (2013). Children's Resources in Collective Households: Identification, Estimation, and an Application to Child Poverty in Malawi. American Economic Review, 103(1):438-71.

Fernández-Villaverde, J. and Krueger, D. (2007). Consumption over the Life Cycle: Facts from Consumer Expenditure Survey Data. Review of Economics and Statistics, 89(3):552-565.

Grosh, M. and Deaton, A. (2000). Designing Household Survey Questionnaires for Developing Countries: Lessons from 15 Years of the Living Standards Measurement Study, volume 17, chapter Consumption. Washington, DC: World Bank. 
Haddad, L., Hoddinott, J., and Alderman, H. (1997). Intrahousehold Resource Allocation in Developing Countries: Models, Methods and Policy. The International Food Policy Research Institute.

Haddad, L. and Kanbur, R. (1990). How Serious Is the Neglect of Intra-Household Inequality? Economic Journal, 100(402):866-81.

Heathcote, J., Storesletten, K., and Violante, G. L. (2005). Two Views of Inequality Over the Life-Cycle. Journal of the European Economic Association, 3(2-3):765-775.

Hong, J. H. and Ríos-Rull, J.-V. (2012). Life Insurance and Household Consumption. American Economic Review, 102(7):3701-3730.

Krueger, D. and Perri, F. (2006). Does Income Inequality Lead to Consumption Inequality? Evidence and Theory. The Review of Economic Studies, 73(1):163-193.

Krueger, D., Perri, F., Pistaferri, L., and Violante, G. L. (2010). Cross Sectional Facts for Macroeconomists. Review of Economic Dynamics, 13(1). Special Issue, January 2010.

Lambert, S., Ravallion, M., and van de Walle, D. (2014). Intergenerational Mobility and Interpersonal Inequality in an African Economy. Journal of Development Economics, 110(C):327-344.

Lise, J. and Seitz, S. (2011). Consumption Inequality and Intra-household Allocations. Review of Economic Studies, 78:328-355.

Lise, J. and Yamada, K. (2014). Household Sharing and Commitment: Evidence from Panel Data on Individual Expenditures and Time Use. IFS Working Papers W14/05, Institute for Fiscal Studies.

Nelson, J. (1988). Household Economies of Scale in Consumption: Theory and Evidence. Econometrica, 56(6):1301-14.

Olken, B. A. (2005). Revealed Community Equivalence Scales. Journal of Public Economics, 89(23):545-566.

Pitt, M. M., Rosenzweig, M. R., and Hassan, M. N. (1990). Productivity, Health, and Inequality in the Intrahousehold Distribution of Food in Low-Income Countries. American Economic Review, 80(5):1139-56.

Salcedo, A., Schoellman, T., and Tertilt, M. (2012). Families as roommates: Changes in U.S. household size from 1850 to 2000. Quantitative Economics, 3(1):133-175.

Santaeulàlia-Llopis, R. and Zheng, Y. (2016). The Price of Growth: Consumption Insurance in China 1989-2009. Unpublished Manuscript, MOVE-UAB, Barcelona GSE and EUI.

Wang, S.-Y. (2011). State Misallocation and Housing Prices: Theory and Evidence from China. American Economic Review, 101:2081-2107. 
Table 1 Summary Statistics: A Cross-Sectional Snapshot, CHNS 1991-2011

\begin{tabular}{lrrrrrr} 
& \multicolumn{2}{c}{1991} & \multicolumn{2}{c}{2000} & \multicolumn{2}{c}{2011} \\
& Rural & Urban & Rural & Urban & Rural & Urban \\
\hline & & & & & & \\
Age & 29.4 & 35.2 & 35.5 & 40.4 & 44.9 & 48.1 \\
Household Size & 4.0 & 3.8 & 3.6 & 3.3 & 3.0 & 2.8 \\
Children < 15 (\%) & 65.3 & 55.3 & 49.3 & 41.2 & 26.8 & 19.8 \\
Weak DR & 0.5 & 0.3 & 0.3 & 0.2 & 0.2 & 0.1 \\
Strong DR & 0.7 & 0.6 & 0.5 & 0.5 & 0.5 & 0.4 \\
Num. Households & 7,722 & 3,670 & 8,476 & 3,850 & 6,836 & 3,364 \\
& & & & & & \\
\hline
\end{tabular}

Notes: This table shows the summary statistics of the demographics and the household structure from the analysis sample that satisfies the sample selection criteria (see Section 2). 
Table 2 Missing Consumption Inequality

\begin{tabular}{lcc} 
& Rural & Urban \\
\hline (a) Food Consumption: & & \\
Individual Inequality & & \\
Adult-Equivalent Inequality & 0.744 & 0.572 \\
Missing Inequality (\%) & 0.436 & 0.355 \\
& 41.48 & 37.71 \\
(b) Core Food Consumption (Excl. "Vices"): & & \\
Individual Inequality & 0.311 & 0.275 \\
Adult-Equivalent Inequality & 0.252 & 0.234 \\
Missing Inequality (\%) & 19.26 & 14.76 \\
& & \\
\hline
\end{tabular}

Notes: Missing consumption inequality is defined as the share of actual individual consumption inequality not captured by adult-equivalent consumption inequality, that is, $\sum_{t} 100 \times\left(1-\frac{\operatorname{var}_{t}\left(\ln c^{h}\right)}{\operatorname{var}_{t}\left(\ln c^{i}\right)}\right)$, where $\operatorname{var}_{t}\left(\ln c^{h}\right)$ is the cross-sectional variance of logged adult-equivalent consumption and $\operatorname{var}_{t}\left(\ln c^{i}\right)$ is the cross-setctional variance of actual individual consumption. We report the average across our eight waves of data. See Section 4 for a discussion. 


\section{Table 3 Missing Consumption Inequality: Households without Children}

\begin{tabular}{lrr} 
& Rural & Urban \\
\hline (a) Food Consumption: & & \\
Individual Inequality & & \\
Adult-Equivalent Inequality & 0.727 & 0.559 \\
Missing Inequality (\%) & 0.512 & 0.408 \\
(b) Core Food Consumption (Excl. "Vices"): & & \\
Individual Inequality & 0.29 .65 & 26.96 \\
Adult-Equivalent Inequality & 0.257 \\
Missing Inequality (\%) & 0.267 & 0.245 \\
& 5.32 & 4.70 \\
\hline
\end{tabular}

Notes: Missing consumption inequality is defined as the share of actual individual consumption inequality not captured by adult-equivalent consumption inequality, that is, $\sum_{t} 100 \times\left(1-\frac{\operatorname{var}_{t}\left(\ln c^{h}\right)}{\operatorname{var}_{t}\left(\ln c^{i}\right)}\right)$, where $\operatorname{var}_{t}\left(\ln c^{h}\right)$ is the cross-sectional variance of logged adult-equivalent consumption and $\operatorname{var}_{t}\left(\ln c^{i}\right)$ is the cross-setctional variance of actual individual consumption. We report the average across our eight waves of data. See Section 4 for a discussion. 
Figure 1 Adult-Equivalent vs. Actual Individual Consumption Inequality: The Cross-Section

\section{Food Consumption}

(a) Rural

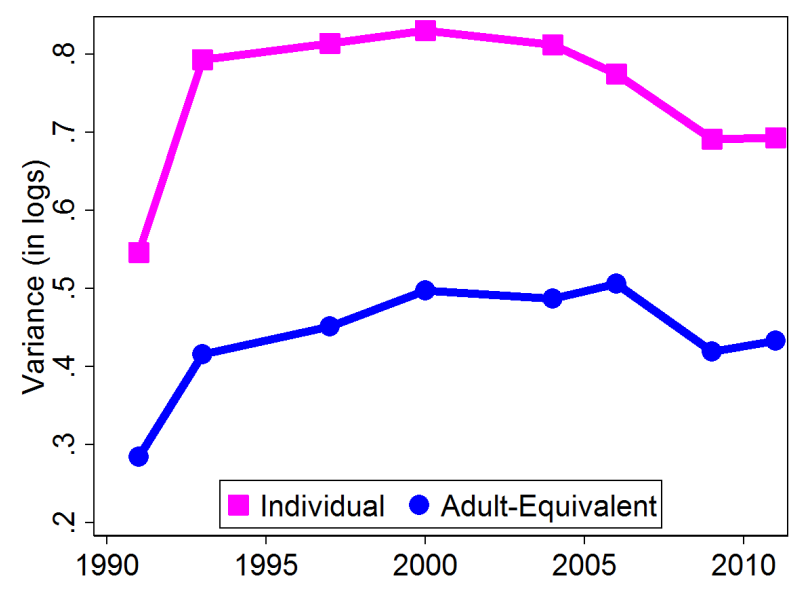

(b) Urban

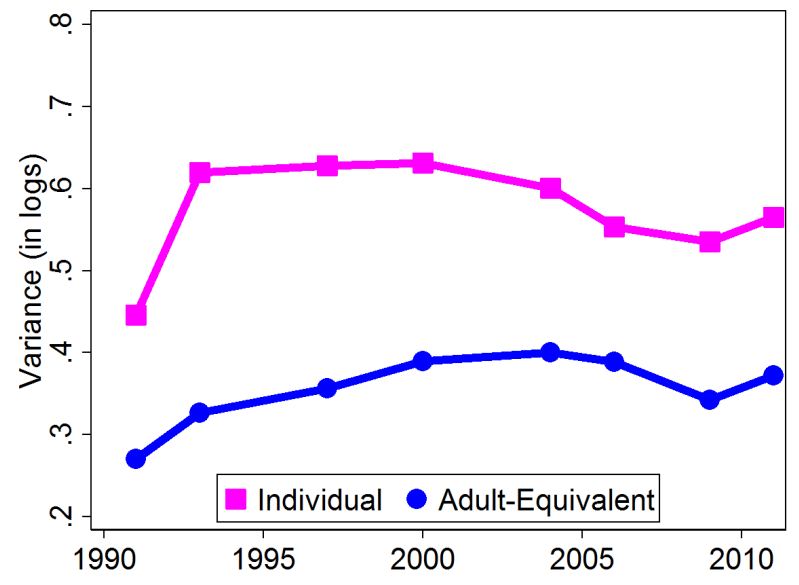

(c) Rural

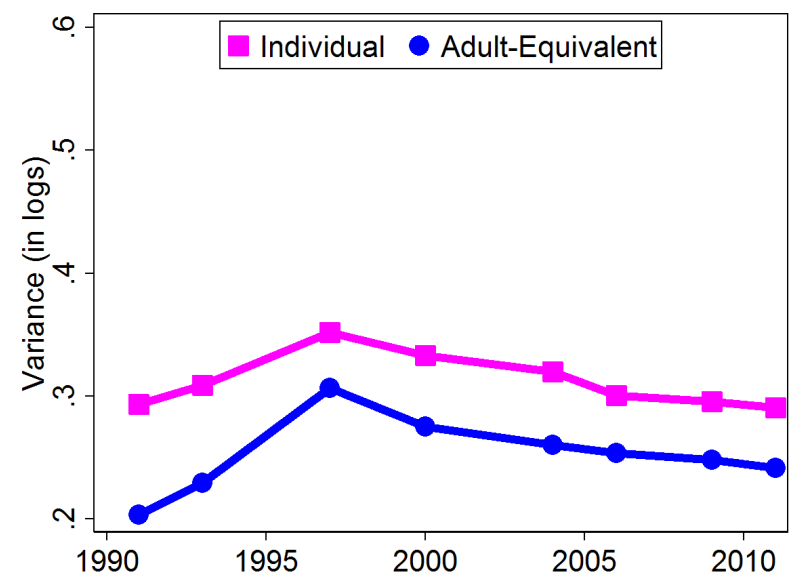

(d) Urban

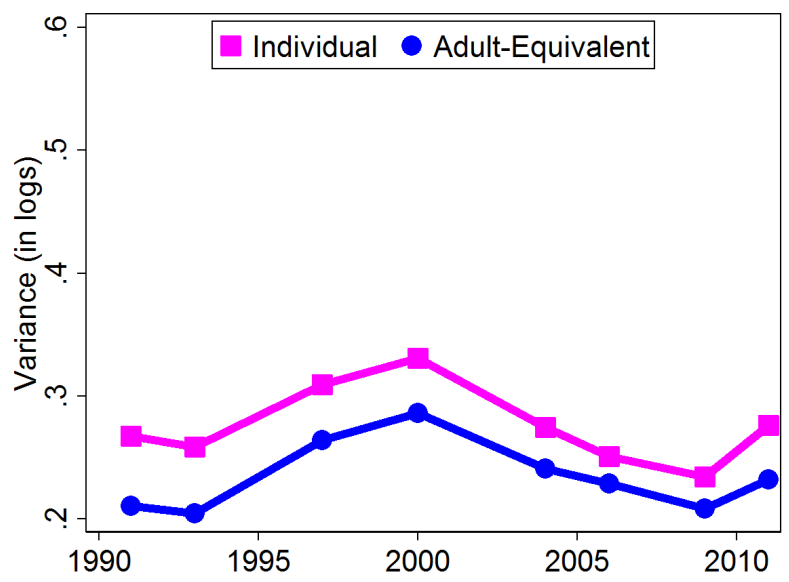

Notes: The measure of inequality is the variance of logged variables. The top panels focus on cross-sectional inequality of food consumption from 1991 to 2011, and the bottom panels focus on cross-sectional inequality of core food consumption (excluding alcohol, tobacco, coffee and tea) from 1991 to 2011. The left panels focus on rural areas, and the right panels on urban areas. See sections 3 and 4 for computation details. 
Figure 2 Adult-Equivalent vs. Actual Individual Consumption Inequality: The Life Cycle

\section{Food Consumption}

(a) Rural

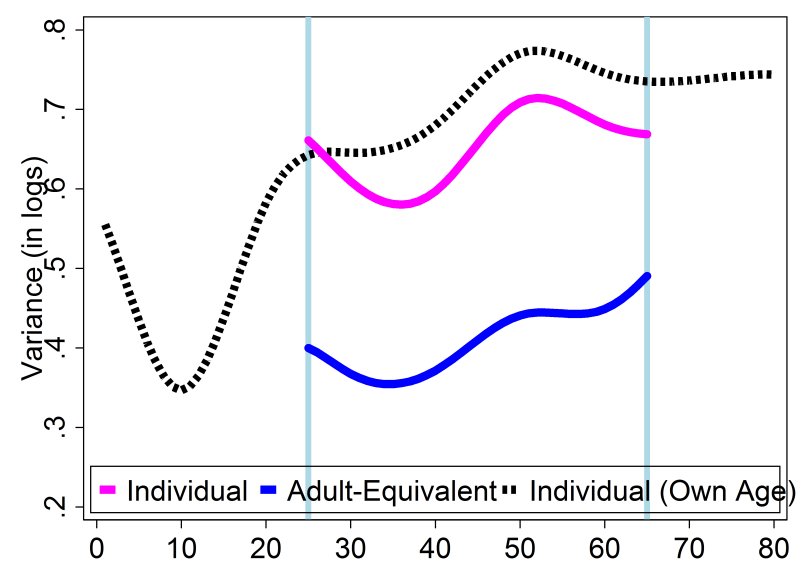

(b) Urban

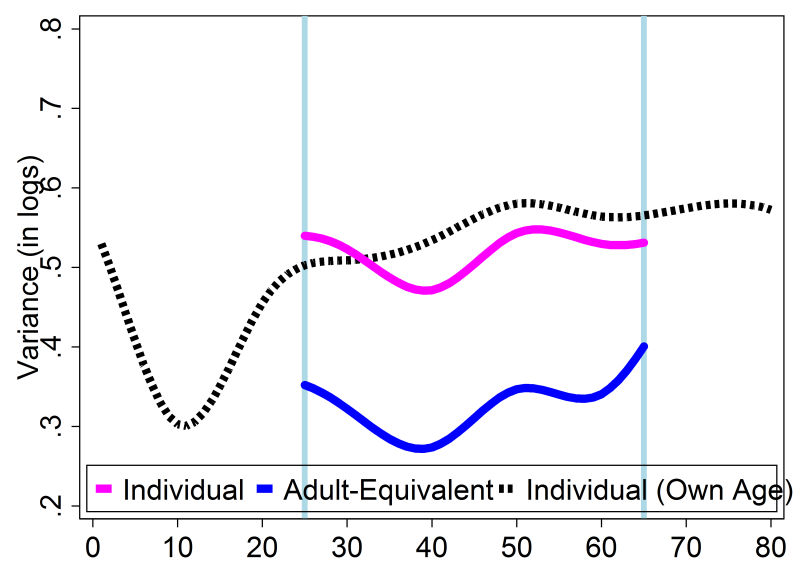

\section{Core Food Consumption (Excluding "Vices")}

(c) Rural

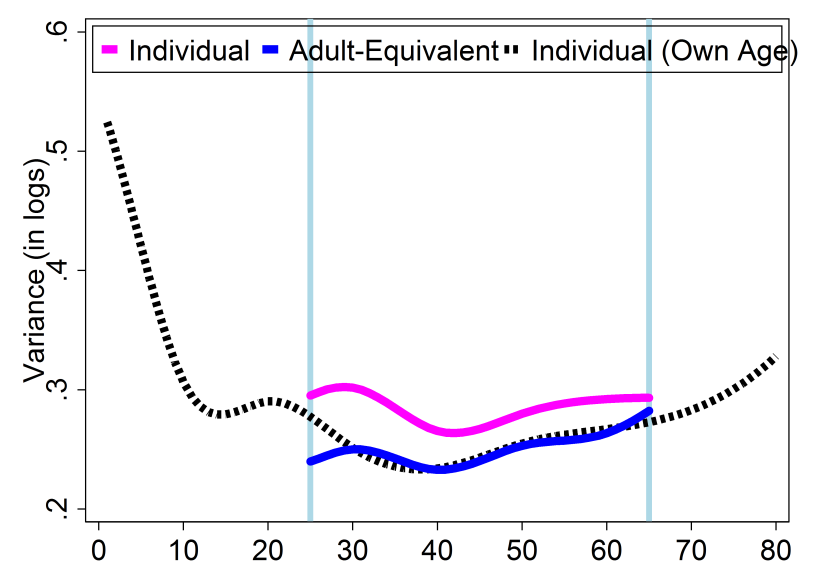

(d) Urban

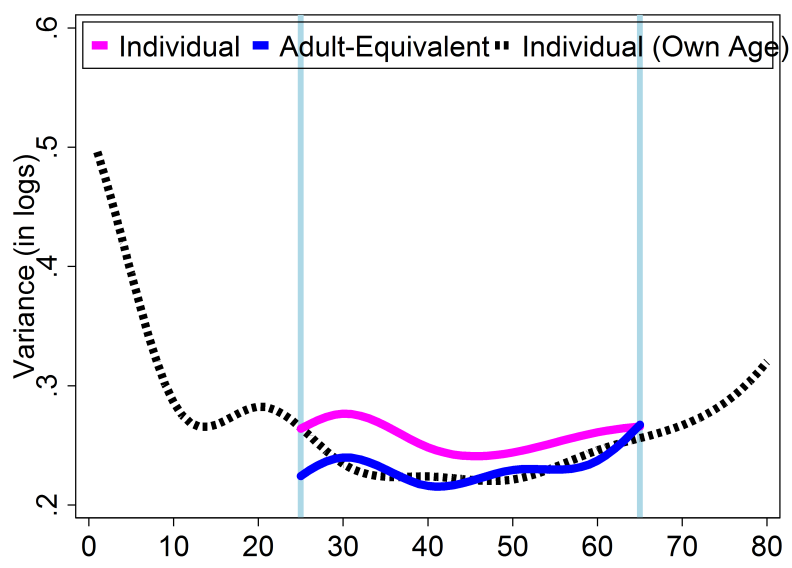

Notes: The measure of inequality is the variance of logged variables. The top panels focus on life cycle inequality of food consumption, and the bottom panels focus on life cycle inequality of core food consumption (excluding alcohol, tobacco, coffee and tea). The left panels focus on rural areas, and the right panels on urban areas. We use cohort controls. See sections 3 and 4 for computation details. 
Figure 3 The Role of Children: Households without Children

The Cross-Section

(a) Core Food Consumption (Excluding "Vices")

(b) Calorie Intake
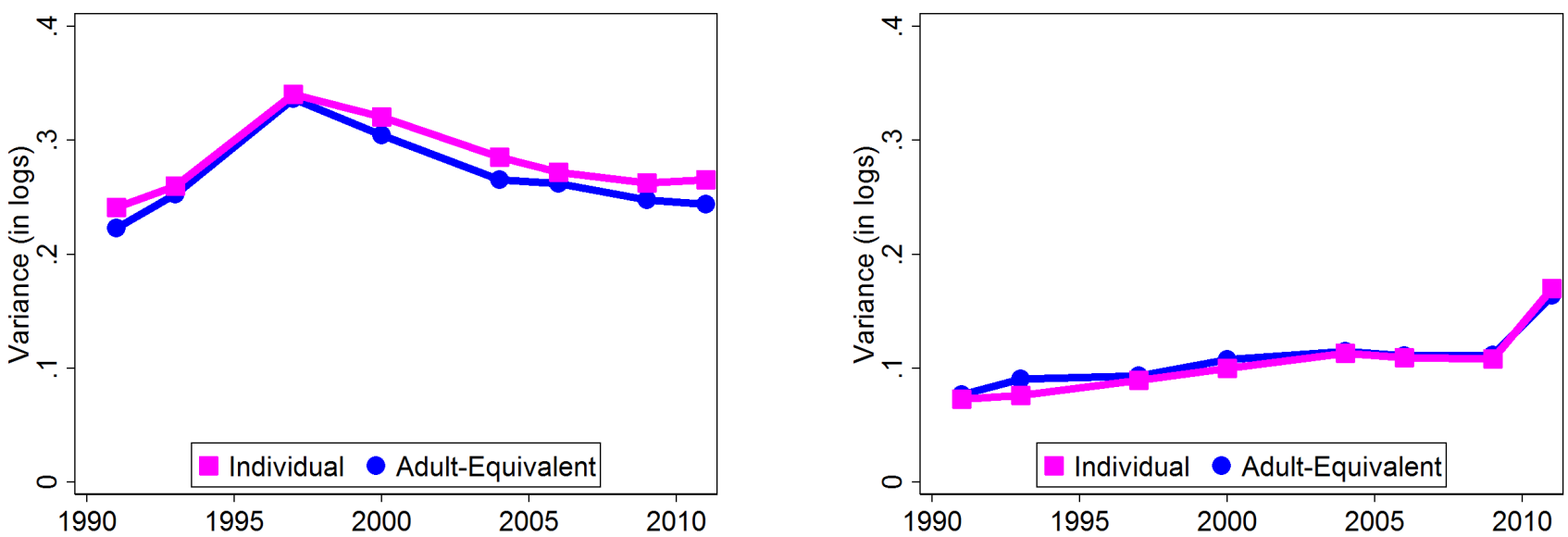

The Life Cycle

(c) Core Food Consumption (Excluding "Vices")

(d) Calorie Intake
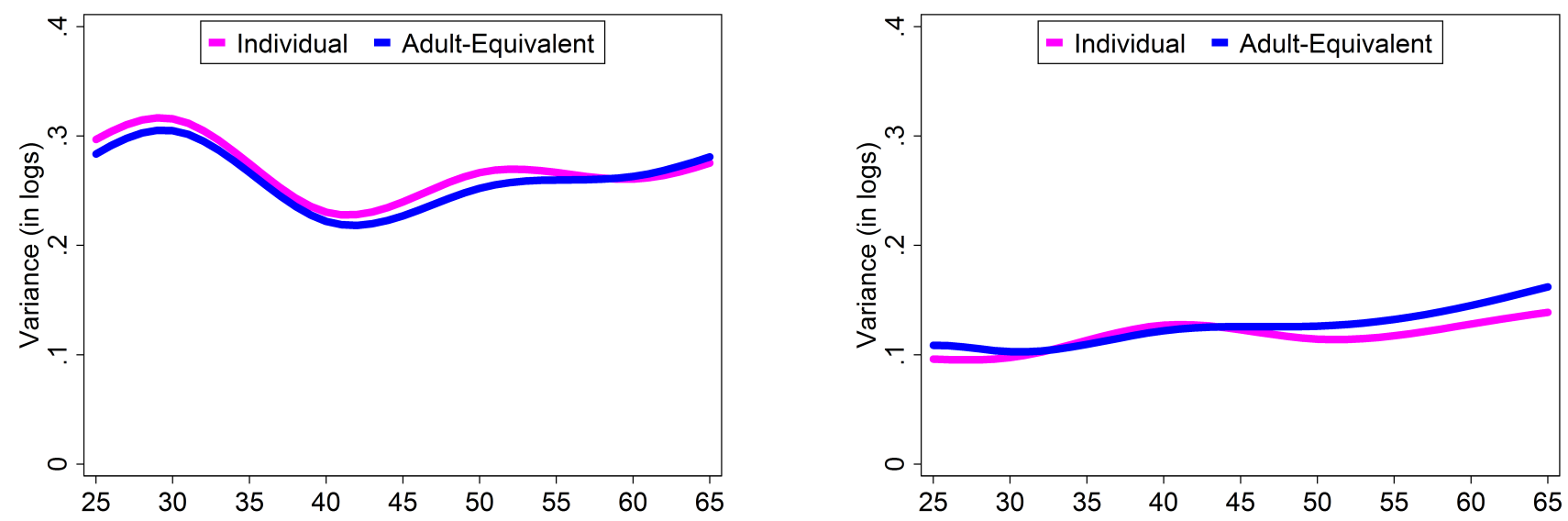

Notes: The measure of inequality is the variance of logged variables. We use a sample of households without children. The top panels focus on cross-sectional inequality of core food consumption and calorie intakes over time, and the bottom panels focus on life cycle inequality of core food consumption and calorie intakes over age. We use cohort controls to compute life cycle inequality. See sections 3 and 4 for computation details. 
Figure 4 Three-Member Household: The Life Cycle

(a) Core Food Consumption (Excluding "Vices")

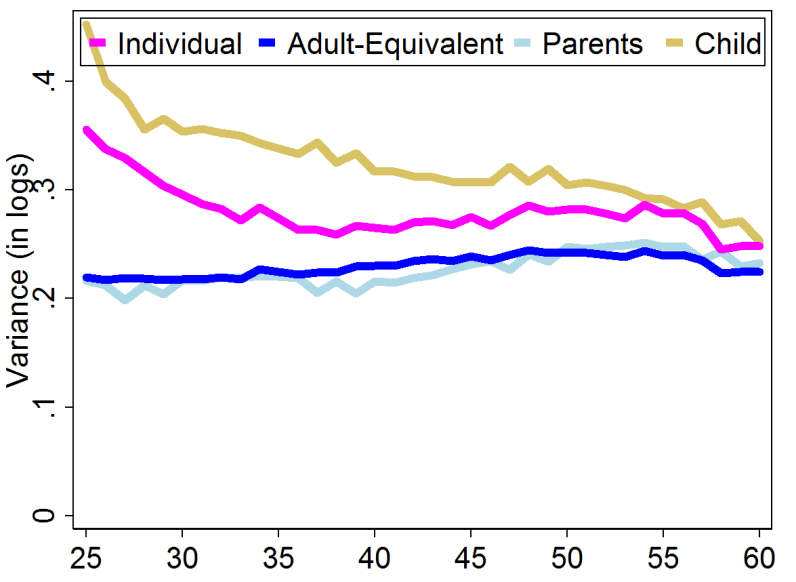

(b) Calorie Intake

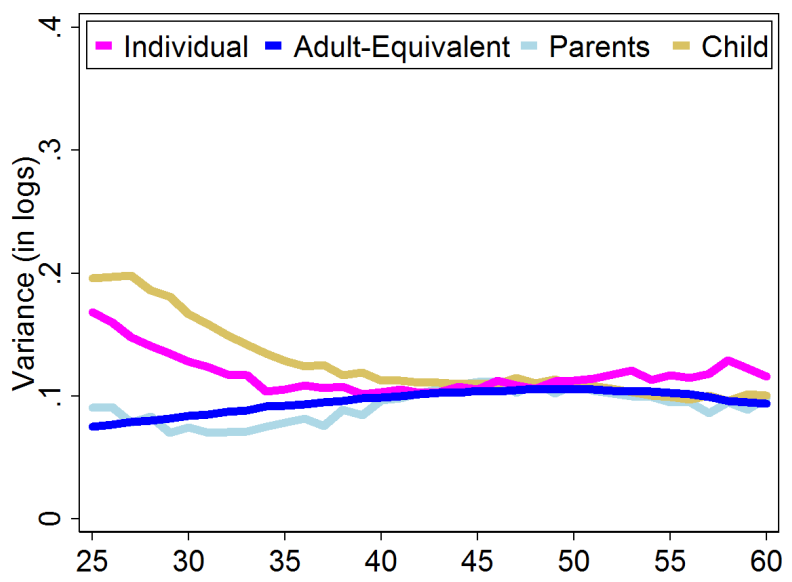

Notes: The measure of inequality is the variance of logged variables. The left panel focuses on the life cycle inequality of core food consumption and the right panel focuses on the life cycle inequality of calorie intake. We use cohort controls. See sections 3 and 4 for computation details. 